\title{
Effect of Long-Term Service on Microstructure and Mechanical Properties of Martensitic 9\% Cr Steel
}

\author{
Grzegorz Golański, Anna Zielińska-Lipiec, Adam Zieliński, and Marek Sroka
}

\author{
(Submitted August 16, 2016; in revised form December 14, 2016; published online February 17, 2017)
}

\begin{abstract}
The paper presents the results of research on the X10CrMoVNbN9-1 (T91) steel after long-term service. The material for testing was taken from a pipe section of a boiler superheater coil serviced for around $105,000 \mathrm{~h}$ at the temperature of $540{ }^{\circ} \mathrm{C}$, at the pressure of $12.5 \mathrm{MPa}$. A quantitative analysis including the measurement of mean diameter of subgrains and precipitates as well as the density of dislocations of the examined steel was performed by means of TEM. The microscopic tests of T91 steel were complemented with the results of tests on mechanical properties which included also the short creep tests. After service, the investigated steel was characterized by a retained lath microstructure of tempered martensite with fine subgrain and quite large density of dislocations as well as numerous precipitates. In the microstructure, apart from the particles of $M_{23} C_{6}$ and $M X(V X, N b C, V$-wings), the precipitates of Laves phase and single particles of $Z$ phase were revealed. It has been shown that the extent of degradation of the T91 steel microstructure was minor, which resulted from its low temperature of service. Performed tests of mechanical properties showed that these properties fulfilled the minimum requirements for this steel in the as-received condition. A favorable influence of fine precipitates of Laves phase on mechanical properties was observed. Moreover, an insignificant influence of single precipitates of $Z$ phase on the creep resistance of the examined steel was stated.
\end{abstract}

Keywords creep and stress rupture, electron, mechanical microscopy, steel

\section{Introduction}

The creep-resistant martensitic T/P91 steel was developed in the 1970 s as a result of the modification and optimization of the chemical composition of P9 steel. It was a response to the needs of the conventional power industry aiming to obtain "pure" carbon technologies. T/P91 steel fills the gap between materials designed for work at elevated temperatures in the conditions of subcritical loads and the alloys that can transfer supercritical and ultra-supercritical states of load. T/P91 steel owes its high properties mostly to solution strengthening with Mo atoms and to precipitation strengthening with fine-dispersive precipitates of $\mathrm{MX}$ and $\mathrm{M}_{23} \mathrm{C}_{6}$ carbides. This steel is characterized by a number of significant qualities that have determined its already broad implementation in the power industry. T/P91 steel was introduced into the power industry in the 1990s, mostly as material for seamless hot-rolled pipes (Ref 1, 2). Many longterm studies were performed on this steel, such as but not limited to, the assessment of the stability of the microstructure and mechanical properties (Ref 3-5), low-cycle fatigue resis-

Grzegorz Golański, Czestochowa University of Technology, Al. Armii Krajowej 19, 42-200 Czestochowa, Poland; Anna Zielińska-Lipiec, AGH - University of Science and Technology, Mickiewicza 30, 30-059 Cracow, Poland; Adam Zieliński, Institute for Ferrous Metallurgy, K. Miarki 12-14, 44-100 Gliwice, Poland; and Marek Sroka, Institute of Engineering Materials and Biomaterials, Silesian University of Technology, ul. Konarskiego 18a, 44-100 Gliwice, Poland. Contact e-mail: marek.sroka@polsl.pl.

tance (Ref 6-8), and weldability (Ref 9, 10). The result of these studies was that the steel was put into service in power units without any major problems.

The condition set for steels used in the power industry is to retain a stable microstructure that enables the maintaining the assumed mechanical properties and high reliability throughout the long service period. Assessment of the reliability (safety) of the elements of pressure devices made of creep-resistant steels is carried out on the basis of the data obtained as a result of many tests. These are performed not only for the materials in the as-received condition but also after service, in various states of degradation of the microstructure and functional properties (Ref 11, 12).

The literature on this matter lacks sufficient data concerning the influence of the actual long-term conditions of service in a power unit on the stability of the microstructure and mechanical properties of new martensitic steels of the $9-12 \% \mathrm{Cr}$ type. The insufficiency of this data has inspired the authors to perform research on the microstructure and mechanical properties of T91 steel after over $105,000 \mathrm{~h}$ of service at the temperature of $540{ }^{\circ} \mathrm{C}$.

\section{Material and Methodology of Research}

The investigated material was pipes sections made of X10CrMoVNb9-1 (T91) steel taken from a boiler superheater coil of the following dimensions: $63.5 \times 7.1 \mathrm{~mm}$. The time of service amounted to over $105,000 \mathrm{~h}$ at the pressure of 12.5 MPa and the temperature of around $540{ }^{\circ} \mathrm{C}$. The chemical composition of the T91 steel is presented in Table 1.

Tests of the microstructure were carried out by means of a transmission electron microscope JEM 200CX (TEM) using thin foils. Thin foils were prepared using conventional double- 
Table 1 Chemical composition of T91 steel (wt.\%)

\begin{tabular}{lccccccccc}
\hline $\mathbf{C}$ & $\mathbf{M n}$ & $\mathbf{S i}$ & $\mathbf{P}$ & $\mathbf{S}$ & $\mathbf{C r}$ & $\mathbf{M o}$ & $\mathbf{V}$ & $\mathbf{N i}$ & $\mathbf{N}$ \\
\hline 0.13 & 0.46 & 0.34 & 0.017 & 0.005 & 8.83 & 0.99 & 0.21 & 0.27 & 0.064 \\
\hline
\end{tabular}

jet electropolishing in a solution of $95 \%$ acetic acid and $5 \%$ perchloric acid at a temperature of $10{ }^{\circ} \mathrm{C}$ and a potential of $40 \mathrm{~V}$. The dislocation density within the subgrains of tempered specimens was measured using the linear intersection method recommended and first used by Ham (Ref 13). Quantitative microstructural characterization was realized using the ImageJ $1.38 \times$ commercial software. The dislocation density inside the martensite/subgrain laths, the size of the subgrains, and the mean diameter of precipitates was measured on the images of the microstructure using AnalysySIS and Image ProPlus software. The subgrain size and the diameter of precipitates were evaluated on the basis of determining the equivalent circle diameter (ECD) (Ref 14). The phases were identified with the use of selective electron diffraction. The details of the TEM procedures are given in Ref 5 and 14.

The scope of the test performed on the mechanical properties included: the static test of tension at room and elevated temperatures, measurement of the hardness, an impact strength test, and short-term creep tests. The impact strength tests were carried out on nonstandard test samples of the Charpy "V" type, with their width reduced to $5 \mathrm{~mm}$. The static test of tension was performed using round test samples with an initial diameter $d_{o}=5 \mathrm{~mm}$. The static test of tension was used to determine: the yield strength (YS), the yield strength at the temperature of $550{ }^{\circ} \mathrm{C}\left(\mathrm{YS}^{550}\right)$, the tensile strength (TS), and elongation (El.).

The measurement of hardness was taken by the Vickers method with the indenter load of $30 \mathrm{~kg}(294 \mathrm{~N})$. The abovementioned tests were run according to the relevant standard guidelines. The results obtained from the tests of the mechanical properties were compared with the data available in the manufacturer's certificate of acceptance of the material.

The creep tests were carried out in single-sample six-stand machines constructed in the Institute for Ferrous Metallurgy. They were equipped with three-zone heaters with the control and regulation system, based on high-quality PLC drivers and extensometers used for elongation measurements, performed by high-resolution inductive distance sensors. Short-term creep tests were conducted at a constant stress level corresponding to the required operating level, i.e., 60,80 , and $100 \mathrm{MPa}$, and at five different test temperature levels, higher than the expected service temperature, i.e., $620,640,660,680$, and $700{ }^{\circ} \mathrm{C}$. A detailed description of the methodology of the short-term creep tests is included in the publication (Ref 15).

\section{Experimental Results}

\subsection{Microstructure of T91 Steel After Service}

The microstructure of T91 steel after long-term service is presented in Fig. 1, illustrating a tempered martensite with a small subgrain with numerous precipitates of diverse size. The mean diameter of subgrains amounted to $789 \pm 207 \mathrm{~nm}$ and their distribution are presented in Fig. 2(a). Inside the subgrains, a relatively high density of dislocations was observed,
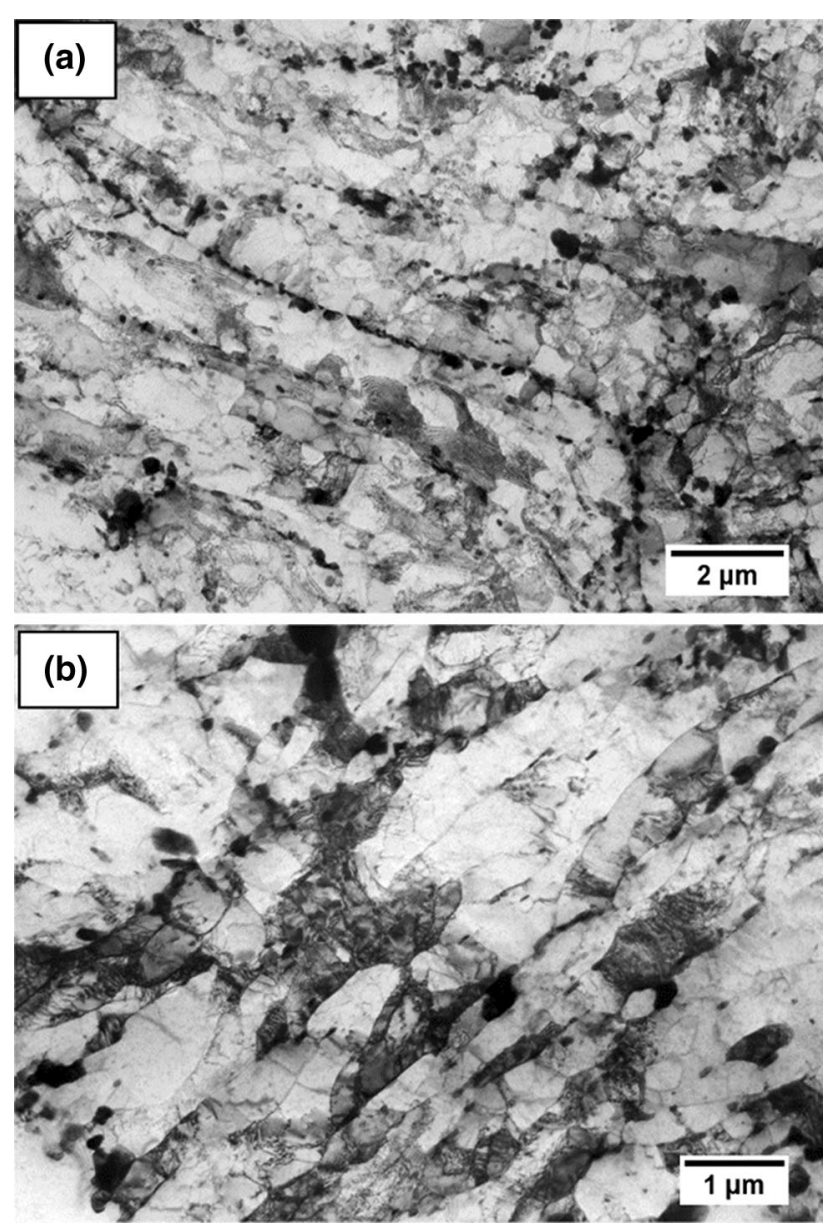

Fig. 1 Microstructure of T91 steel after long-term service: (a) continuous grid of precipitates on the boundary of prior austenite grains; (b) subgrain microstructure

the average density of dislocations amounted to $2.47 \pm 0.78 \times 10^{14} \mathrm{~m}^{-2}$.

The precipitates were observed mostly on the boundaries of prior austenite grain, on the boundaries of martensite laths, and on the boundaries of subgrains, as well as inside these subgrains. In some places, the number of precipitates was so big that they formed the so-called continuous grid of precipitates [see Fig. 1(a)]. In the microstructure of T91 steel after service, the presence of the precipitates of MX type (Fig. 3) $\mathrm{M}_{23} \mathrm{C}_{6}$ carbides and Laves and $\mathrm{Z}$ phase [Fig. 4(a)] was apparent. Inside the subgrains, mostly fine-dispersive precipitates of MX were observed (Fig. 3). Some of them were precipitated on the dislocations. In the investigated steel, three types of MX precipitates were observed: NbC carbides, VX carbonitrides/nitrides, and composite complexes of precipitates named "V-wings." Precipitates of the "V-wings" type are particles consisting of a spherical $\mathrm{NbC}$ precipitate on which lamellar VX precipitates nucleate $(\operatorname{Ref} 2,5)$. The mean diameter of MX precipitates after service amounted to $25 \pm 6 \mathrm{~nm}$. These precipitates are seen as a very effective 

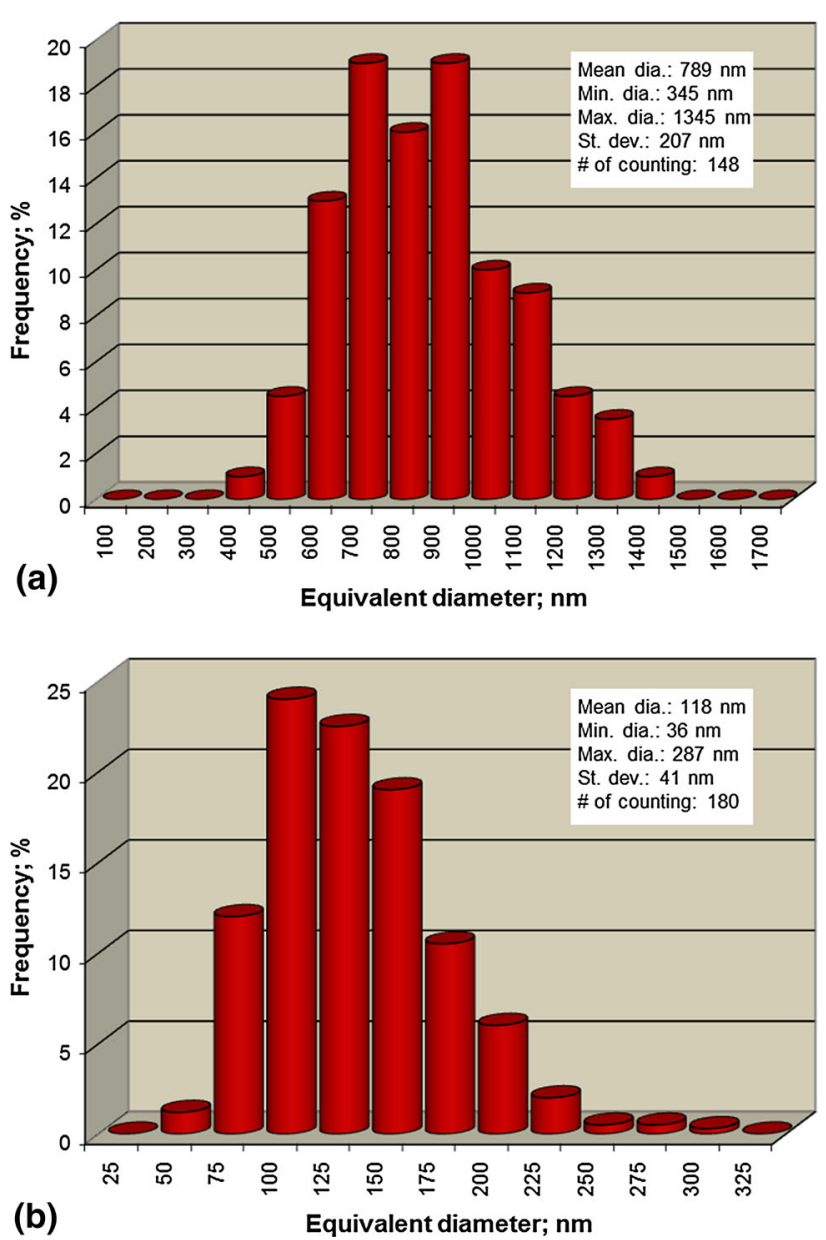

Fig. 2 Overall distributions of (a) subgrain and (b) $\mathrm{M}_{23} \mathrm{C}_{6}$ carbide precipitates in the T91 steel after service

factor limiting the mobility of dislocations (Fig. 5), and their effectiveness depends on size and volume fraction (Ref 2, 5).

The $\mathrm{M}_{23} \mathrm{C}_{6}$ carbides and Laves phase were found to distribute along the boundaries of prior austenite grain and the boundaries of subgrains [Fig. 4, 6(a)]. Precipitates of $\mathrm{M}_{23} \mathrm{C}_{6}$ carbides and Laves phase were observed also inside the subgrains and in the subgrain corners, respectively. The precipitates of the Laves phase were revealed on the boundaries of prior austenite grains, frequently near the $\mathrm{M}_{23} \mathrm{C}_{6}$ carbides. The mean diameter of $\mathrm{M}_{23} \mathrm{C}_{6}$ carbides in T91 steel after service amounted to $118 \pm 41 \mathrm{~nm}$ and their distribution are presented in Fig. 2(b).

In the examined steel, some single precipitates of the $\mathrm{Z}$ phase compound $\mathrm{Cr}(\mathrm{V}, \mathrm{Nb}) \mathrm{N}$ nitride were also noticed [Fig. 6(b)].

\subsection{Mechanical Properties of T91 Steel}

The properties of the examined steel after service in the asreceived condition (according to the steel manufacturer's certificate of acceptance) and the minimum standard requirements are presented in Fig. 7 and Table 2.

Figure 8 presents the results of short-term creep tests of the examined steel. The way of performing the short-term creep tests was verified in the long-term creep tests (Ref 11, 15, 25). In engineering practice, short-term creep tests are used to determine the time of further safe operation of the steel types
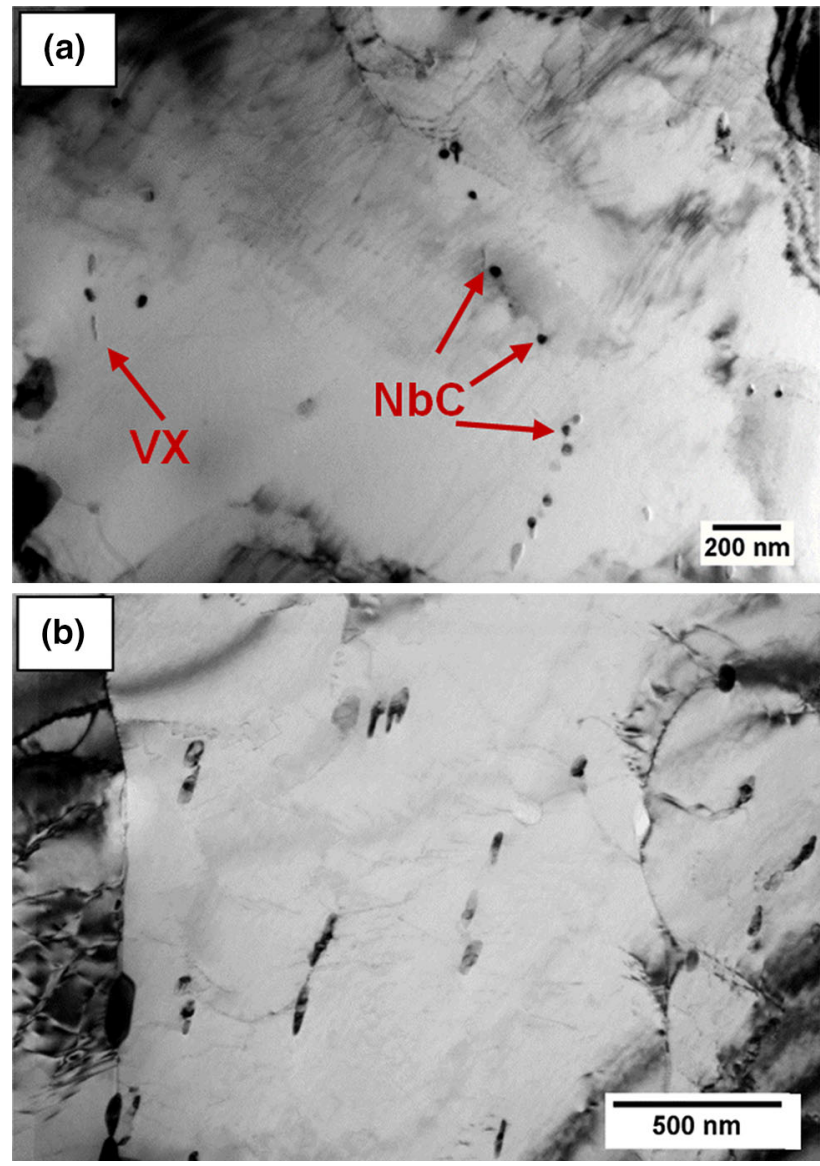

Fig. 3 Morphology of MX precipitates in the examined steel: (a) $\mathrm{NbC}$ and VX; (b) V-wings

serviced beyond the calculative service time ( $\operatorname{Ref} 25,26)$. The evaluated time to rupture for the assumed parameters of work and the safe time of further service defined as 0.6 of the time to rupture (Ref 26) are presented in Table 3 . The available life 0.6 determines the time to $t_{\mathrm{r} 0.6}$ rupture close to the end of II state of creep. This value limits the critical degree of degradation of the material in which the irreversible internal damages identified with III state of creep (accelerated creep) can occur (Ref 25).

\section{Discussion}

In the as-received condition, namely after hardening and tempering, the high-chromium martensitic steels are characterized by a metastable microstructure that will evolve as a result of service in the creep conditions. The magnitude of the changes in the microstructure of the $9 \% \mathrm{Cr}$ steel is mostly dependent on the temperature of service. The lack of quantitative data concerning the microstructure of the examined steel in the as-received state limits the possibility of comparative analysis concerning the changes that occur during the actual service of the T91 steel.

In the as-received state, the dislocation substructure of the $9 \% \mathrm{Cr}$ steel is characterized by a small elongated subgrain with a mean diameter ranging from around 250 to around $500 \mathrm{~nm}$, and by large density of free dislocations inside the subgrains, 

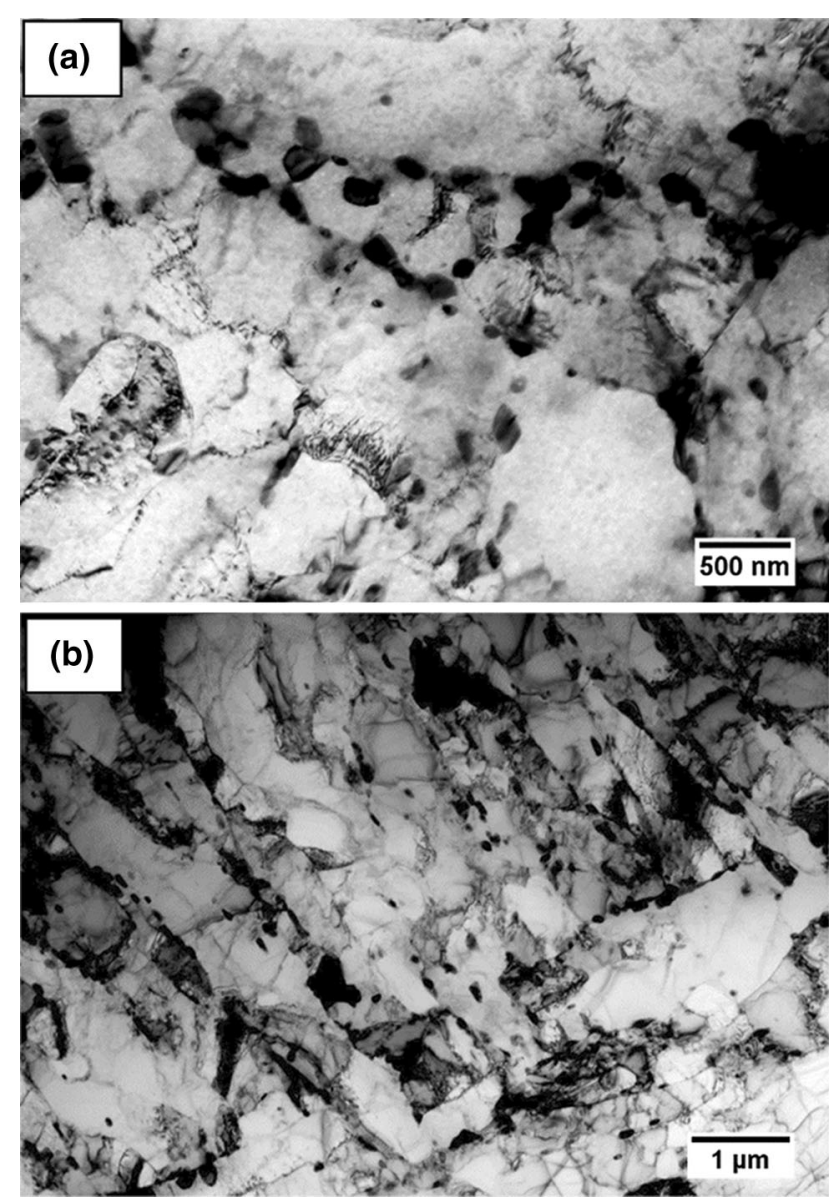

Fig. 4 Precipitates of $\mathrm{M}_{23} \mathrm{C}_{6}$ carbides on the subgrain boundary (a), heterogeneous distribution of precipitates in the microstructure (b)

amounting to $4-8 \times 10^{14} \mathrm{~m}^{2}$ (Ref $\left.2,3,16,17\right)$. The recovery process running during the service leads to a gradual disappearance of the lath character of the microstructure, a decrease in the density of free dislocations inside the grains, and the formation and growth of the size of subgrains (Ref 3, 5, 14). The size of subgrains is an important factor that has an influence on high creep resistance (Ref 16). The growth of subgrains is caused by the state of metastable equilibrium reached between the processes of strengthening (as a result of creeping) and softening (as a result of the processes of recovery and polygonization which lead to a fall of the steel properties).

Matrix softening is a process that is activated thermally. An elevated temperature causes a decrease in the resistance of the lattice and generates a growth of the concentration of vacancies, which makes it easier for the dislocations to bypass obstacles with the mechanism of climb. This leads to the microstructure recovery shown by the disappearance of the lath martensite microstructure, the process of polygonization and repolygonization, as well as a fall in the dislocation density as a result of their progressive ordering, annihilation, and entangling in the boundaries (Ref 14). The process of annihilation of the mobile dislocations is a predominant mechanism of the decrease in their density $(\operatorname{Ref} 3,16)$. It has been reported that the motion of the free dislocations caused by their interaction results in a reduction of systematic free energy (Ref 18).

At the lower temperature, the ability of dislocations to move in the crystal lattice is lower, and the diffusion processes

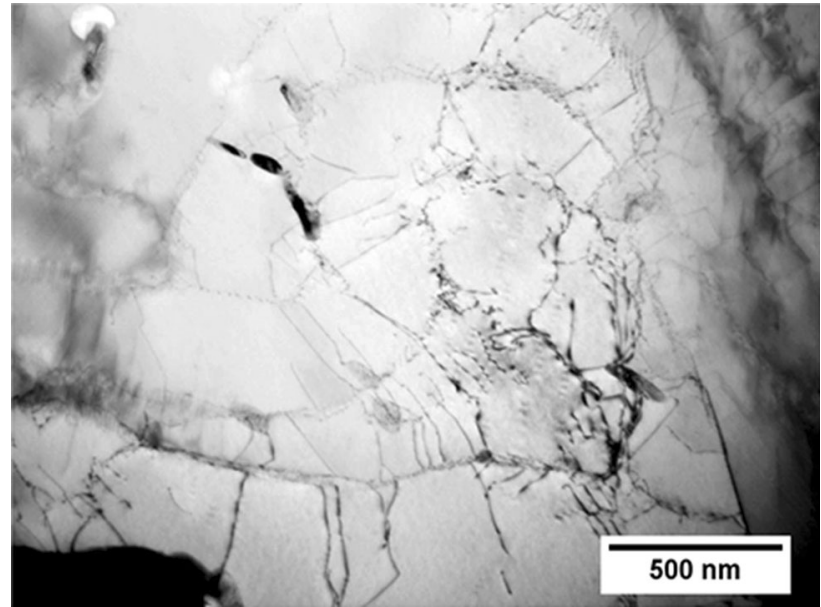

Fig. 5 Interaction of dislocations inside the subgrain with MX precipitates
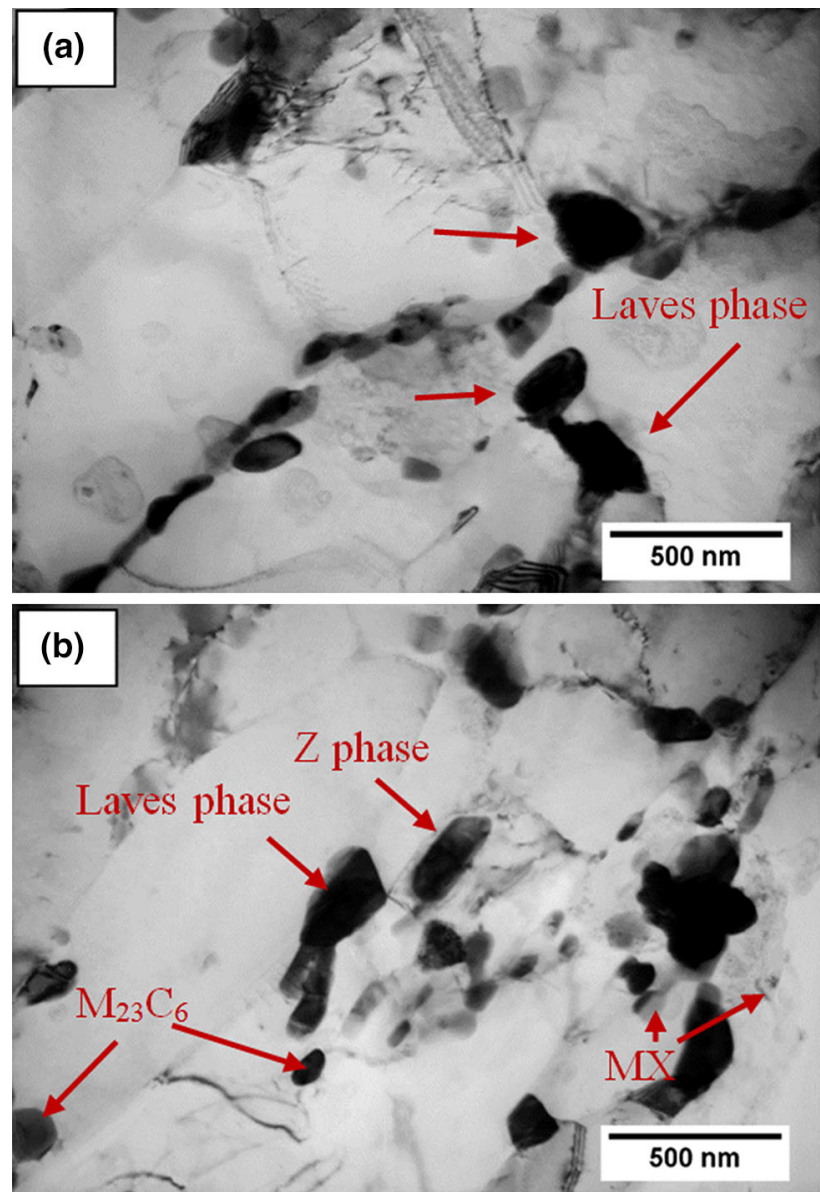

Fig. 6 Precipitates of Laves phase (a) and $Z$ phase (b) in the microstructure of T91 steel after service, precipitates indicated with arrows

activated thermally run more slowly. At the same time, the dislocation substructure is stabilized by the precipitation. Hence, the relatively high density of the dislocations and the relatively small subgrains are still maintained. Small degree of advancement of the matrix softening process is also reflected by 


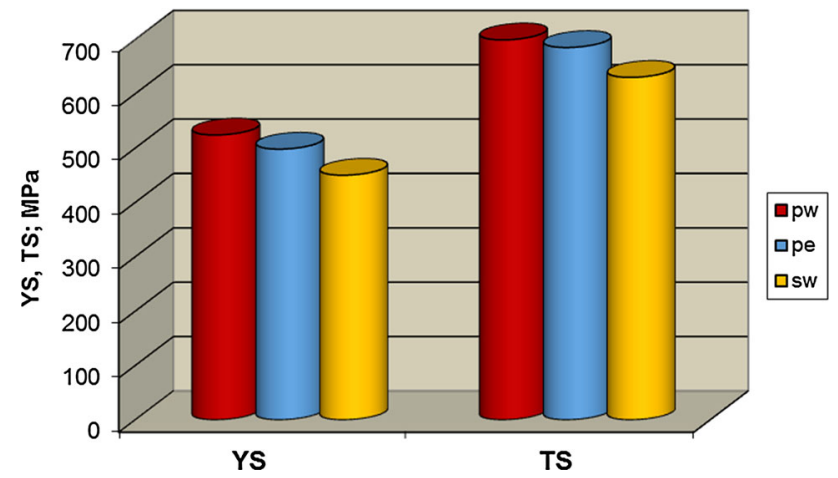

Fig. 7 Properties of T91 steel in the as-received state (sw), after service (pe) compared with the minimum requirements for this grade of steel (pw)

Table 2 Mechanical properties of T91 steel after service

\begin{tabular}{|c|c|c|c|c|}
\hline \multicolumn{3}{|c|}{$\mathrm{KCV}_{2} 300 / 5$} & \multirow[b]{2}{*}{$\mathrm{YS}_{\mathbf{0 . 2}}^{550} \mathrm{MPa}$} & \multirow[b]{2}{*}{ HV30 } \\
\hline $\mathbf{J}$ & $\mathrm{J} / \mathrm{cm}^{2}$ & $\mathbf{K} \mathbf{V}_{\mathbf{c}}{ }^{*}$ & & \\
\hline 49 & 123 & 98 & 337 & 212 \\
\hline \multicolumn{5}{|c|}{ Requirements according to Ref 24} \\
\hline 27 & & & 270 & $\ldots$ \\
\hline \multicolumn{5}{|c|}{$\begin{array}{l}\text { * The value of impact strength calculated from the relation } \\
\mathrm{KV}_{c}=\left(10 \times \mathrm{KV}_{p}\right) / w ; \mathrm{KV}_{p} \text { - the value of impact strength obtained on } \\
\text { a nonstandard test sample; } J, w \text { - the width of the nonstandard tes } \\
\text { sample; mm (Ref 24) }\end{array}$} \\
\hline
\end{tabular}

high-strength properties (YS, TS, $\mathrm{YS}^{550}$ ) of the examined steel compared with the as-received condition (Fig. 7; Table 2).

The size of subgrains in the steel subject to the creeping process is conditioned on the stress state and temperature. Stability of the dislocation subgrain microstructure in steel of the $9-12 \%$ Cr type during service depends on the morphology of the $\mathrm{M}_{23} \mathrm{C}_{6}$ carbides precipitated on the boundaries of grains (Ref 16). According to the Zener mechanism, the stability increases together with the growth of the number of particles precipitated on the boundaries and with the degree of their dispersion. The retained lath microstructure and relatively fine subgrains (Fig. 1, 4) indicate the role maintained by the $\mathrm{M}_{23} \mathrm{C}_{6}$ carbides as an inhibiting factor for the migration of dislocation boundaries. It has a favorable influence on maintaining highstrength properties and creep resistance (Fig. 7, 8; Tables 2, 3). Especially as the literature data $(\operatorname{Ref} 27,28)$ show that the main

Table 3 Time to rupture determined on the basis of short-term creep tests and safe time of further service of T91 steel for the assumed parameters of further operation

\begin{tabular}{|c|c|c|c|}
\hline \multirow[b]{2}{*}{$\begin{array}{l}\text { Assumption } \\
\text { operating } \\
\text { stress } \sigma_{r}, \mathrm{MPa} \\
\end{array}$} & \multirow{2}{*}{$\begin{array}{c}\text { Assumption } \\
\text { temperature } \\
\text { of further } \\
\text { operation } T_{n},{ }^{\circ} \mathrm{C}\end{array}$} & \multicolumn{2}{|c|}{ Determined life, $\mathrm{h}$} \\
\hline & & $\begin{array}{l}\text { Time } \\
\text { to rupture }\end{array}$ & $\begin{array}{c}\text { Safe } \\
\text { operation } \\
\text { time }\end{array}$ \\
\hline \multirow[t]{4}{*}{100} & 580 & 130,000 & 78,000 \\
\hline & 570 & 300,000 & 180,000 \\
\hline & 560 & $>500,000$ & 420,000 \\
\hline & 550 & $>500,000$ & $\sim 500,000$ \\
\hline
\end{tabular}

mechanism of strengthening in martensitic steels of the $9-12 \%$ $\mathrm{Cr}$ type is the strengthening with grain boundaries and the solution strengthening constituting, respectively, 33 and $29 \%$ of the yield strength increase. Nevertheless, in the longer term, these precipitates will be subject to the process of coagulation during service, which leads to a reduction of their number, assuming their constant volume fraction as per Ostwald's law (Ref $5,14,16)$. As a consequence, this will contribute to a decrease in their role as the subgrain growth inhibitor.

The retained high properties of the examined steel after long-term service can result from the additional precipitation strengthening with fine particles of the Laves phase. Influence of the Laves phase on strength properties can be considered from two angles. On the one hand, the precipitation and fast growth of the Laves phase, due to low stability, contributes to the matrix depletion of chromium and molybdenum. It leads to a reduction in the solution strengthening, which can consequently contribute to an increase in the susceptibility of the steel to the process of polygonization of the matrix, reduction of creep strength, and increase in brittleness and oxidation resistance (Ref 20, 29, 30). Still, the matrix depletion of substitution elements, being also the components of $\mathrm{M}_{23} \mathrm{C}_{6}$ carbides, has a favorable influence on the moderation of the coagulation process of these precipitates (Ref 14). On the other hand, the precipitation of secondary particles of Laves phase results in the growth of precipitation strengthening in the initial stage, which causes an increase in the strength properties. In the initial period of service, the Laves phase precipitates can be a factor that stabilizes the subgrain size (Ref 29), partly compensating the matrix depletion of substitution elements. At the same time, the fine precipitates of the Laves phase do not have an influence on the reduction of fracture toughness of the steel. Nevertheless, due to the high susceptibility of this phase to coagulation, this effect disappears rather quickly (Ref 2, 21). The high properties of the examined steel probably indicate an initial stage of precipitation of this phase.

In the microstructure of the investigated steel, some of the boundaries of the laths/subgrains were observed to be unfilled with precipitates [Fig. 4(b)]. Boundaries with a misorientation angle less than $20^{\circ}$ are not the preferred places for carbide precipitation, which results from their low energy (Ref 19, 20). The small misorientation angle of these boundaries is also the cause of their limited mobility, which ensures the relative stability of the grain substructure, even after very long periods (Ref 16).

The main requirement set for the creep-resistant steels working at elevated temperatures is high creep resistance. The cause of the degradation of $9-12 \% \mathrm{Cr}$ steel microstructure in the creep conditions lies in the migration of dislocations and subgrain boundaries. The growth of creep resistance is connected with stable precipitates inhibiting the movement of dislocations and stabilizing the subgrain microstructure (Ref 2, $5,14,16)$. Fine-dispersive MX carbonitrides pinning the dislocations, as observed in the steel after long-term service, is what confirms the high stability of these precipitates because, according to the literature data (Ref $2,5,14,17)$, their size in the as-received state is determined at the level of around $20 \mathrm{~nm}$. An increase in the stability of the particles of $\mathrm{M}_{23} \mathrm{C}_{6}$ carbides, and Laves phase precipitates has a positive influence on the growth of creep resistance, among other things as a result of introducing the microaddition of boron (Ref 31$)$. The occurrence of the precipitates of $Z$ phase in the microstructure results in the disappearance of precipitation strengthening. The 
precipitation of $\mathrm{Z}$ phase is accompanied by the disappearance of fine-dispersive MX precipitates. It is assumed that every large precipitation of the $\mathrm{Z}$ phase is formed as a result of the solution of around 1500 particles of MX (Ref 22). This results in the disappearance of strengthening of the precipitation mechanism with these fine-dispersive particles. Consequently, it leads to an accelerated fall of creep strength (Ref 22) and a considerable decrease in hardness compared with the strength properties (Ref 32). In creep-resistant martensitic steels containing over $10 \% \mathrm{Cr}$, the occurrence of the $\mathrm{Z}$ phase precipitates

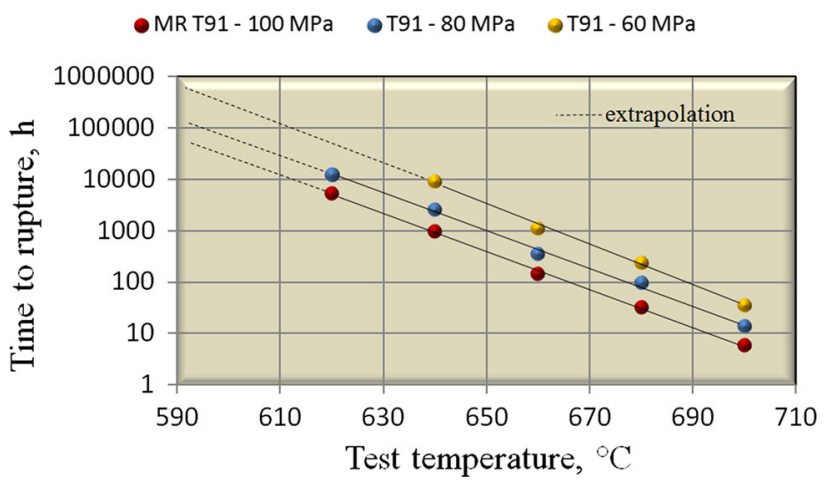

Fig. 8 Results of short-term creep tests of T91 steel

in the microstructure contributes to a very rapid fall of the creep strength (Ref 22). The observed high hardness (Table 2), as well as the evaluated long time of safe service of T91 steel (Fig. 8; Table 3), indicates a relatively minor scope of changes in the morphology of precipitates. In the investigated steel, an interaction of quite numerous precipitates of MX with dislocations was still observed (Fig. 5). The observation of very rare particles of the $\mathrm{Z}$ phase in the examined steel is confirmed by thermodynamic calculations of the kinetics of the precipitation of this phase in P91 steel. These calculations show that the beginning of the $\mathrm{Z}$ phase precipitation in the time exceeding $100,000 \mathrm{~h}$ is possible (Ref 23). It can therefore be suggested that the precipitation of $\mathrm{Z}$ phase did not have an influence on a significant decrease in the density of MX precipitates in this case. The results obtained from the short-term creep tests also show that single particles of the $\mathrm{Z}$ phase do not have a negative influence on the properties of $9 \% \mathrm{Cr}$ steel. The mechanical properties of the investigated steel after over $105,000 \mathrm{~h}$ of service fulfilled the minimum requirements for new materials.

\section{Conclusions}

The investigated material was T91 steel after over 105,000 h of service at the temperature of $540{ }^{\circ} \mathrm{C}$. Analyzing the changes in the microstructure of T91 steel after service was difficult due to the lack of qualitative data of the microstructure in the asreceived state. After long-term service of the examined steel, degradation of the microstructure was observed. It consisted in the recovery process, precipitation of Laves phase, and probably the related matrix depletion of substitution elements, the beginning of the transformation of MX-type precipitates into $\mathrm{Z}$ phase and the privileged precipitation of precipitates on the boundaries of prior austenite grains. Because of the low temperature of service of the examined steel, as for this grade of material, the changes in the microstructure were not very advanced, in spite of the long service time. The relatively small degree of microstructure degradation in T91 steel was reflected in the obtained mechanical properties. These properties were higher than the minimum ones set for this grade of steel in the as-received condition. It was shown that the fine particles of $\mathrm{M}_{23} \mathrm{C}_{6}$ carbides and Laves phase precipitates had a favorable influence on maintaining high properties throughout the long service period. Therefore, the moderation of the process of growth of these precipitates is one of the main ways of increasing the microstructure stability in $9 \% \mathrm{Cr}$ steel. It was also proved that the single particles of $\mathrm{Z}$ phase revealed in the microstructure did not have a negative influence on its creep resistance.

\section{Acknowledgments}

The results in this publication were obtained as part of the research co-financed by the National Centre for Research and Development under contract PBS3/B5/42/2015-Project: "Methodology, evaluation and forecast of operation beyond the analytical operating time of welded joints of pressure components of power boilers."

\section{Open Access}

This article is distributed under the terms of the Creative Commons Attribution 4.0 International License (http://creative commons.org/licenses/by/4.0/), which permits unrestricted use, distribution, and reproduction in any medium, provided you give appropriate credit to the original author(s) and the source, provide a link to the Creative Commons license, and indicate if changes were made.

\section{References}

1. A. Iseda, M. Kubota, Y. Hayase, S. Yamamoto, and K. Yoshikawa, Sumitomo Search, 1988, 36, p 17-30

2. J. Hald, Int. J. Press. Vessel Pip., 2008, 85, p 30-37

3. A. Orlova, J. Bursik, K. Kucharava, and V. Sklenicka, Mater. Sci. Eng. $A, 1998, \mathbf{2 4 5}, \mathrm{p}$ 39-48

4. J.H. Baek, S.H. Kim, C.B. Lee, and D.H. Hahn, Met. Mater. Int., 2009, 15, p 565-573

5. C.G. Panait, A. Zielińska-Lipiec, T. Kozieł, A. Czyrska-Filemonowicz, A.-F. Gourgues-Lorenzon, and W. Bendick, Mater. Sci. Eng. A, 2010, 527, p 4062-4069

6. G. Junak and M. Cieśla, Arch. Mater. Sci. Eng., 2011, 48(1), p 19-24

7. Z.H. Wei, H. YiZh, Z. Hui, and C.Y. Wan, Int. J. Fatigue, 2013, 47, p 83-89

8. S. Mroziński and G. Golański, Mater. Res. Innov., 2014, 18, p 504-508

9. S. Spigarelli and E. Quadrini, Mater. Des., 2003, 23, p 547-552

10. H. Li and D. Mitchell, Steel Res. Int., 2013, 84(12), p 1302-1308

11. A. Zieliński, M. Miczka, B. Boryczko, and M. Sroka, Arch. Civ. Mech. Eng., 2016, 4, p 813-824

12. A. Zieliński, G. Golański, and M. Sroka, Kovove Mater, 2016, 54(1), p 61-70

13. R.K. Ham, Philos. Mag., 1961, 6, p 1183-1184

14. G. Golański, A. Zielińska-Lipiec, S. Mroziński, and C. Kolan, Mater. Sci. Eng. A, 2015, 627, p 106-110

15. A. Zieliński, G. Golański, M. Sroka, and J. Dobrzański, Mater. Sci. Technol. Lond., 2016, 32(8), p 780-785 
16. H. Ghassemi-Armaki, R.P. Chen, K. Maruyama, M. Yoshizawa, and M. Igarashi, Mater. Lett., 2009, 63, p 2423-2425

17. L. Cipolla, S. Caminada, D. Venditti, H.K. Danielsen, and A. Di Gianfrancesco, in J. Lecomte-Beckers, Q. Contrepois, F. Kuhn, T. Beck (Eds.), Materials for Advanced Power Engineering, Belgium, 2010, p 270-283

18. G. Gupta and G.S. Was, Metall, Mater. Trans., 2008, 39A, p 150-164

19. M.S. Laws and P.J. Goodhew, Acta Metall., 1991, 39, p 1525 1533

20. Y. Xu, X. Zhang, Y. Tian, C. Chen, Y. Nan, H. He, and M. Wang, Mater. Charact., 2016, 111, p 122-127

21. J.S. Lee, H.G. Armaki, K. Maruyama, T. Muraki, and H. Asahi, Mater. Sci. Eng. A, 2006, 428, p 270-275

22. H.K. Danielsen and J. Hald, VGB PowerTech, 2009, 5, p 68-73

23. B.S. Srinivas Prasad, V.B. Rajkumar, and K.C. Hari Kumar, Calphad, 2012, 36, p 1-7
24. PN-EN 10216-2 Seamless Steel Tubes for Pressure Purposes-Technical Delivery Conditions. Part 2: Non-Alloy and Alloy Steel Tubes with Specified Elevated Temperature Properties

25. J. Dobrzański, Materials Science Interpretation of the Life of Steels for Power Plants, Open Access Library 3, Gliwice, 2011

26. A. Zieliński, G. Golański, M. Sroka, and T. Tański, Mater. High Temp., 2016, 33(1), p 24-32

27. Q. Li, Mater. Sci. Eng. A, 2003, 361, p 385-391

28. K. Maruyama, K. Sawada, and J. Koike, ISIJ Int., 2001, 41, p 641-653

29. F. Abe, Metall, Mater. Trans., 2005, 36A, p 321-332

30. V.T. Paul, S. Saroja, and M. Vijayalakshmi, J. Mater. Nucl., 2008, 378, p 273-281

31. E. Plesiutschnig, C. Beal, S. Paul, G. Zeiler, and C. Sommitsch, Mater. High Temp., 2015, 32(3), p 318-322

32. G. Golański, A. Zieliński, J. Słania, and J. Jasak, Arch. Metall. Mater, 2014, 59, p 1357-1360 